\title{
A Dynamic Sorghum (Sorghum Bicolor (L.) Moench) diversity Management in Situ and Livelihood Resilience in South and Central Tigray Region, Ethiopia
}

\section{*Yemane Tsehaye, Zeratsion Abera, Afewerk Kebede and Berhane Ghebremichael}

Department of Dryland Crops and Horticultural Sciences, College of Dryland Agriculture and Natural Resources, Mekelle University, Mekelle, Ethiopia (*yemtse@yahoo.com)

\begin{abstract}
Sorghum is an important crop for the south and central parts of Tigray Region of Ethiopia. To assess the level of sorghum diversity, two zones, namely South and Central Tigray were selected and eighteen villages in three woredas, Alamata, Raya-Azebo and Tanqua-Abergelle, were surveyed. A total of 93 randomly selected farmers were interviewed using a structured questionnaire that elicited information on socioeconomic aspects of households, sorghum plots, the number and types of farmers' local varieties grown in the area, variety characteristics, seed exchange systems and seed flow together with selection criteria's as well as seed selection process and management. A total of 165 collections belonging to 31 locally named sorghum varieties were retrieved and stored at Mekelle University. High diversity in terms of landrace richness were found the Alamata area $($ Margalef $=2.92$; Menhinick $=1.66$ ) followed by Raya-Azebo (Margalef $=2.61$; Menhinick $=1.46$ ) and Tanqua-Abergelle was found to be less diverse in terms of number of named varieties (Margalef $=1.40$; Menhinick $=1.0$ ). Diversity estimated based on evenness indices showed that Tanqua-Abergelle has the highest diversity (Shannon $=0.86$; Brillouin index $=0.86$ ) followed by Raya-Azebo (Shannon $=0.85$; Brillouin index $=0.85$ ). The lowest evenness was found in Alamata woreda (Shannon $=0.77$; Brillouin index $=0.77$ ). Based on the varietal richness and use values, four sites (villages) that could serve as seed repositories were identified. The result of the econometric analysis indicated that a combination of factors, such as year of schooling, labour equivalence, tropical livestock unit, and number of parcels were the most important determinants that affect significantly the intra-specific diversity. The regression analysis indicates the positive linkage between land fragmentation and landrace richness. The increase in diversity over temporal scale of ten years found in this study revealed that the level of genetic erosion needs numerical evidence to substantiate. The socioeconomic factors that affect varietal diversity and possible conservation and incentive strategies are discussed.
\end{abstract}

Key words: Sorghum, Diversity, Seed flow, Genetic erosion, Resilience

\section{INTRODUCTION}

Ethiopia is one of the Vavilovian centers of origin/diversity for many cultivated and wild species of crops including sorghum (Vavilov, 1951; Harlan, 1971). Sorghum is one of the crops for which Ethiopia has been credited as being a Vavilovian center of origin 
(Vavilov, 1951) and/or diversity (Harlan, 1992). It is an economically, socially and culturally important crop grown over a wide range of ecological habitats in the country, in the range of 400-3000 masl (Teshome et al., 2007). Sorghum is the single most important cereal in the lowland areas because of its drought tolerance (Kebede, 1991). In the high altitude areas, the indigenous germplasm has often been the only adapted materials suitable for use. In Ethiopia, there exist intermediate as well as wild and weedy forms are there (Doggett, 1988). Introgression between the wild (Sorghum bicolor subsp. arundinaceum) and the cultivated sorghum is very likely as both kinds often grow in sympatry with the wild and weedy relatives in many sorghum growing parts of Ethiopia, mainly in south east and south west part of the country (Doggett, 1988). In addition to introgression, disruptive selection that involves selecting simultaneously (mainly conscious selections) for more than one level of a particular character in sorghum populations is probably the main reason for the complexity and wide polymorphism in the sorghum crop (Doggett, 1988).

From Ethiopia many ideas of agriculture and the early-cultivated sorghums, moved along the margin of aquatic culture towards the west (Doggett, 1988). A number of important traits reported about the Ethiopian species include a devastating resistant to pest, sorghum midge (Contarinia sorghicola) (Doggett, 1988), and high lysine and protein contents (National Research Council, 1996). Among the several lines identified resistance to sorghum midge was the SC lines mostly of zera-zera lines from Ethiopia (Doggette, 1988).

The Tigray region, part of the Abyssinian center, is one of the sorghum growing regions in the country and rich for race durra-caudatum and 'Zurru' durras similar to the 'pigmouth' durras of India (Doggett, 1988). Based on qualitative morphology characterization work on Ethiopian as well as introduced lines of sorghum, Ayana and Bekele (1998) reported that the genetic materials from Tigray had high frequency of loose and semi-loose panicle types with erect primary branches, as well as compact and semi-compact panicle types, yellow coloured glumes and leaf midribs and large frequency of awned spikes. They also reported a large diversity estimate, pooled across traits $\left(H^{\prime}=0.76 \pm 0.05\right)$, in sorghum genotypes sampled from this region, that showed their significance in the improvement work of the sorghum crop. 
The continued cultivation and management of traditional varieties including those of sorghum is dynamic and considered as de facto conservation in situ (Bellon, 1996). In situ (on-farm) conservation allows a dynamic adaptation of the plant species into the environment and this phenomenon is particularly important in areas of diversity/origin where crops are enriched by gene exchange with wild or weedy relatives as well as farmers informal seed exchange systems.

The management and enhancement of plant genetic resources including sorghum by farmers on-farm, however, was a neglected conservation strategy (Brush, 1995) and the primary reason was concern over genetic erosion that resulted from dissemination of modern cultivars into the traditional farming systems (Hawkes, 1983). The introduction of improved varieties into a given farming system often considered as a threat that leads to loss of genetic variability (Frankel, 1970) and the presence of modern varieties in farming systems is usually taken as prime facie evidence of genetic erosion (Brush, 1999). The Global Plan of Action for the Conservation and Sustainable Utilization of Plant Genetic Resources for Food and Agriculture and the Convention on Biological Diversity (CBD) also stressed that the farmers demand to grow improved cultivars for many reasons, including market conditions, often that result in significant on-farm genetic erosion. The concern for the rapid loss of genetic resources and crop vulnerability linked to the spread of modern varieties leads to the establishment of ex situ gene banks in many countries including Ethiopia.

The validity of the genetic erosion concept from the indirect measurement of diffusion of modern cultivars rather than the actual loss of local materials outlined above is, however, seriously questioned by some authors (Brown, 1983; Wood and Lenn, 1997; Brush 1999). The concept of genetic erosion describes processes that take place over time and which require measurements of biological variability. Time series data on crop populations and agricultural systems are not generally available for crops or agriculture in centers of diversity in developing countries including Ethiopia. Data on pre-modern crop populations are rare because the question posed by genetic erosion arose after these populations had been affected by technological changes (Brush, 1999). The conclusion that the introduction of high-yielding, uniform cultivars necessarily results in a wipe-out of indigenous varieties fails to recognize the intelligence and sound judgment that is 
characteristic of most farmers (Brown, 1983). Besides, Brush (1999) also argued that the heterogeneity of farming systems in centers of diversity (including Ethiopia) limits the diffusion of modern varieties and maintains production spaces for indigenous varieties.

Therefore, the present study was initiated with the following main objectives: [1] Assess the level of sorghum temporal diversity (both landrace richness and evenness) in Central and South Tigray and the farmers' agrobiodiversity management systems, [2] Identify areas suited for enhancement of on-farm conservation programmes in south and central Tigray, and [3] Estimate the level of genetic erosion.

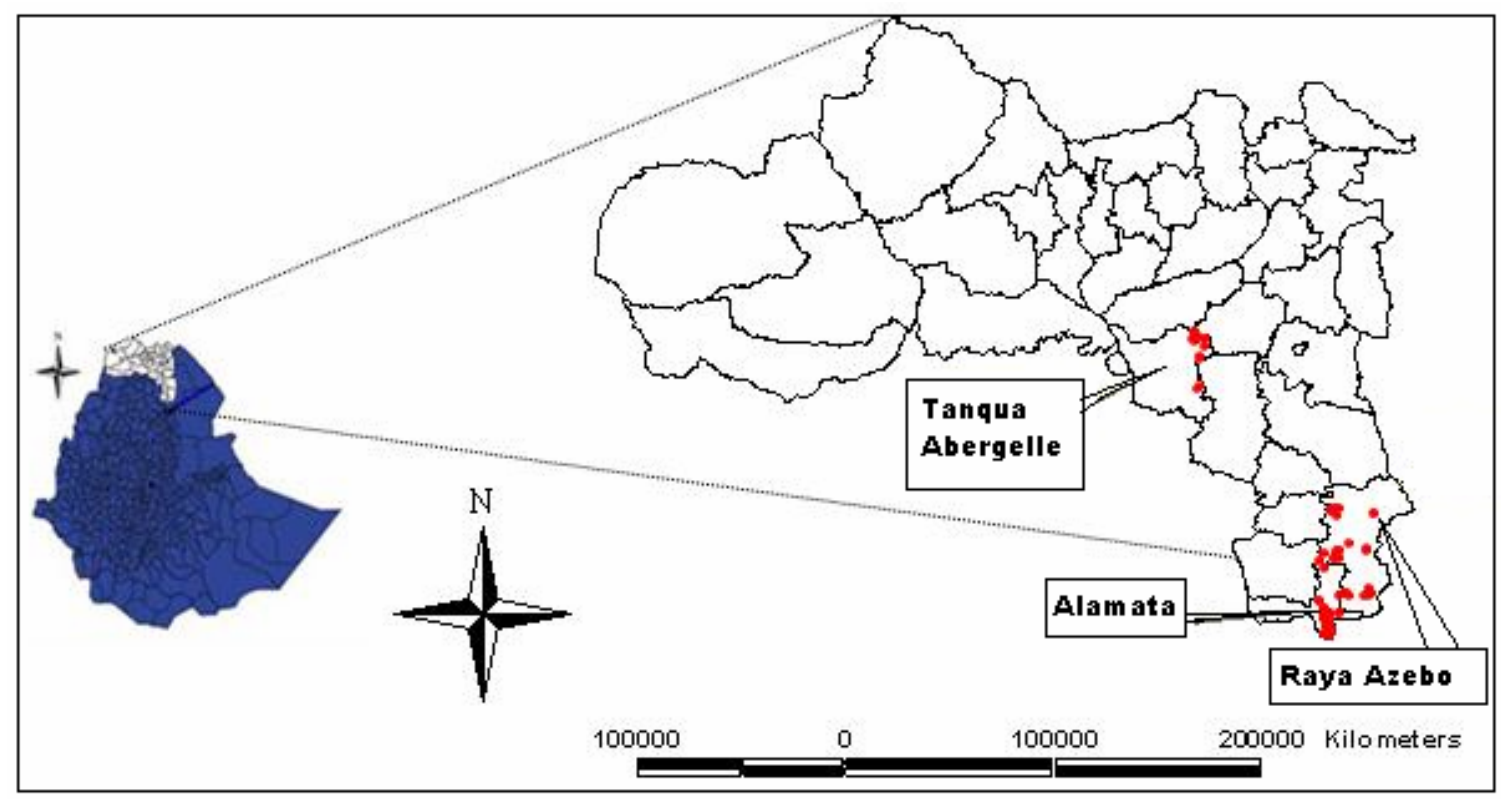

Figure 1. Map of the Tigray Region of Ethiopia showing the study area (Dotted parts show the collection villages).

\section{METHODOLOGY}

\subsection{Description of the study area}

The research was conducted in two sorghum growing zones (central and south Tigray) of the Tigray Region (Fig.1). The geographic areas of the two sorghum growing zones, south (Alamata and Raya-Azebo) and central Tigray (Tanqua-Abergelle) are separated by more than $100 \mathrm{kms}$. In addition to the geographic separation, there are soil and climate differences between the two major zones. Most of the soils in central Tigray is classified as Leptosols (Shallow soils over hard rock or in unconsolidated very gravely material) 
and the majority of the soils from south Tigray are classified as Cambisol, Vertisol and Fluvisols (FAO, 1998). Though bi-modal, the annual rainfall also varies widely in space and in time, in the south than in the central Tigray (site with a uni-modal rainfall pattern). However, the rainfall pattern in the central Tigray area has usually short duration and low distribution. In both zones, sorghum is the dominant crop and cultural practices continue to be relatively traditional and draft animals are used for ploughing and cultivation. The sorghum crop is sown and harvested manually and chemical inputs including fertilizers are seldom used in both zones.

\subsection{Sampling}

Two districts/woredas (Alamata and Raya-Azebo) in south and one woreda (TanquaAbergelle) in central Tigray were purposively selected for this particular study, as these three woredas were well known for sorghum production. Six sites (villages) in Alamata area, nine sites in Raya-Azebo and three sites in Tanqua-Abergelle were surveyed.

A total of 93 sorghum growing households (22-75 age range) were randomly selected from the three districts (woredas). In each selected household, the farmer in charge of agricultural production was identified and interviewed using a structured questionnaire that elicited information on socioeconomic characters of households, sorghum plots, the number and types of varieties grown in the area, variety characteristics, seed exchange system and seed flow, selection criteria's as well as seed selection and management. In some occasions a focus group discussion were done with elder men and women farmers on over all status of the sorghum agrobiodiversity. After or at harvest samples of sorghum panicles were collected from 93 households before threshing. On average one un-threshed panicle of sorghum from each independently named variety within a given farm were collected to estimate the amount of on-farm sorghum diversity in terms of counting farmer-named varieties (Teshome, 1996; Tripp, 1996). Information on associated indigenous knowledge provided by the farmers donating the samples was documented for further analysis. A checklist of varieties of sorghum landraces (variety register) existing on the study area was also documented. The level of consistency in naming and distinguishing local varieties in the folk classification were also assessed. Varieties that have been grown ones but currently reported to be lost from the area were also recorded. 


\subsection{Statistical analysis}

\subsubsection{Ecological models}

Ecological models that are widely used in quantitative ethnobotany were employed to analyze the level of diversity. All models have been adapted from the literature on species diversity (Magurran, 1988), although here landraces were used as analogy to species. Magurran (1988), define species diversity as consisting of two components: (1) the number of species (richness-R) and (2) how equally abundant the species are (evenness-E).

A number of diversity indices are employed using landraces as a unit and the models are given below.

- The McIntosh's index $(U)$ of diversity is estimated as follows:

$$
\left.U={\sqrt{\left(\sum n_{i}\right.}}^{2}\right)
$$

where $n_{i}$ is the proportional abundance of the $i^{\text {th }}$ variety

The evenness (E) measure of the McIntosh's index of diversity is obtained as follows:

$$
E=\frac{N-U}{N-N / \sqrt{S}}
$$

where $N$ total number of landraces sampled and $S$ refers to number of landraces

- Shannon Diversity Index $(H)$ is estimated as:

$$
H=-\sum p i \ln p i
$$

where $p_{i}$, the proportional abundance of the $i^{\text {th }}$ landraces $=\left(n_{i} / N\right)$

The evenness (E) measure of the Shannon Diversity Index is calculated as follows:

$$
E=H / \ln S
$$

- The Brillouin index $(H B)$, a useful measure that has better discriminant ability in situation when the number of species and their proportional abundance remain constant (Stiling, 2002), is estimated as follows:

$$
H B=\frac{\ln N !-\sum \ln n_{i} !}{N}
$$


The evenness (E) of the Brillouin index was estimated as given by Stiling (2002).

- Two simple landraces richness measures, Margalef's index $\left(D_{M g}\right)$ and Menhinick's index $\left(D_{M n}\right)$ are employed as follows:

$$
\begin{aligned}
D_{M g} & =(S-1) / \ln N \\
D_{M n} & =S / \sqrt{N}
\end{aligned}
$$

- $\quad$ Berger-Parker index, a dominance index that is weighted towards the abundance landrace is estimated as:

$$
D_{B P}=\frac{N_{\max }}{N}
$$

where $N_{\max }$ is the number of individuals in the most abundant landrace and $N$ is the total number of all individuals in all landraces. To express greater diversity with a numerically greater value, the reciprocal form of the index is used.

- Geometric series, a model most commonly applied to species-poor assemblage is employed as a tool to measure abundance of the varieties. The basic assumption in this model is that the dominant species will use proportion $k$ of some limiting resources, the second most dominant species will take proportion $k$ of the remainder and so, until all species have been accounted for. The model is given as follows:

$$
n_{i}=N C_{k} k(1-k)^{i-1}
$$

where $\quad k=$ the proportion of the available niche space or resource that each varieties occupies

$$
\begin{aligned}
& n_{i}=\text { the number of individuals in the } \mathrm{i}^{\text {th }} \text { variety } \\
& \mathrm{N}=\text { the total number of individuals } \\
& C_{k}=\left[1-(1-k)^{s}\right]^{-1}, \text { and is a constant which ensures that } \sum n_{i}=N
\end{aligned}
$$

\subsubsection{Genetic erosion models}

- Genetic integrity (GI) and Genetic erosion (GE) was estimated as given by Hammer et al. (1996).

$$
G I_{\%}=\left(C_{Y 2} / C_{Y 1}\right) \times 100
$$


where $Y 1$ refers to number of landraces collected in the initial year (first collection mission) and Y2 refers to the number of landraces collected in the second collection (second collection mission).

$G E_{\%}=100 \%-G I$

\subsubsection{Island biogeography model}

The island biogeography model suggests that the number of species on an island is affected by the size of the island and by the proximity of the island to a source pool of colonists. Large islands hold more species than small islands (MacArthur and Wilson, 1967). Much higher correlation between the size of an island and species richness forwarded as a support to the island biogeography theory. However, direct application of the island theory into agricultural biodiversity conservation is not possible as the traditional farming system is highly influenced by farmers' conscious and unconscious selection exercises and preferences, as the farmers concern is more diverse that they focus on multiple attributes. Brush (1999) questioned the definition of the area that was given by large area more specie/diversity model. He also noted that the level of diversity that might found in a given area is rather more important than the land size and this could be tested at morphological, biochemical and molecular levels.

We hypothesis that the number of landraces grown by a given household could be affected by the number of extant field patches/islands (plots) the household owned. To ascertain this hypothesis a model was developed as follows:

$$
L=c P^{s}
$$

$\log \mathrm{L}=\log \mathrm{c}+\mathrm{s} \log \mathrm{P}$

where, $L$, refers to varieties, $C$ is constant measuring the number of local varieties per unit parcels (plots), $s$ is slop and $P$ refers to the log of the number of parcels.

\subsubsection{Econometric methods}

The primary interest of the socioeconomic analysis as part of this research is to identify factors that influence sorghum diversity in south and central Tigray and to devise a possible on-farm conservation strategy. As the data completely relied on count of landraces that take on non-negative integer values, poisson regression was estimated and the model is formulated as follows: 


$$
f(y i)=\frac{\mu^{y} e^{-\mu}}{y !}
$$

where, the mean parameters is a function of the regressors $\mathbf{x}$, and a parameter vector, $\beta$

$$
\begin{aligned}
& E(y i)=\mu=\exp \left(x_{i}^{\prime} \beta\right) \text { and } \\
& y=0,1,2 \ldots V(y i)=\mu\left(x_{i}, \beta\right)=\exp \left(x_{i}^{\prime} \beta\right)
\end{aligned}
$$

Among the diversity indices, Margalef's index was found suitable to be used as a dependent variable against several socioeconomic and environmental variables for the regression analysis. Margalef index (measure of richness) is adapted from the field of ecology that is usually used as measure of spatial species diversity (Magurran, 1988). The number of sorghum varieties encountered in each household is measured by a Margalef index adjusted based on the area share, i.e. the proportion of the crop area that is planted to each variety of sorghum in each household. The Margalef index estimated based on the area share was used as a dependent variable against other determinants and the equation is formulated as follows:

$$
\text { - } \quad \text { Margalef }\left(\mathrm{D}_{\mathrm{Mg}}\right)=(S-1) / \ln A_{i}
$$

where, $A_{i}$ is total area planted to each local variety by the household and $S$ is number of sorghum varieties grown by the household

\section{RESULTS}

\subsection{Spatial distribution of sorghum local varieties}

Documenting farmer-named varieties is important from the genetic resources conservation and utilization point of view, as the names farmers give to varieties is the unit that farmers manage and select over time. Altogether 13, 12 and 6 locally named farmers' varieties (total 165 samples of varieties collected) were collected (stored at the Mekelle University) from Alamata, Raya-Azebo and Tanqua-Abergelle areas respectively (Table. 1).

Farmers in the study area named the sorghum varieties they grow and identify them by certain characteristics, including panicle shape, seed color, peduncle shape, stature height, maturity, sweetness of the stalk, etc. The list of the varieties grown in each respective woreda's is given in table 1. Most of the varieties collected were reported to 
suite to a number of end-uses as farmers in the study areas use them for a multiple purposes. The sorghum agrobiodiversity in the study area is highly associated with livestock production and usually organic with no or limited use of chemical fertilizers.

Table 1. List of varieties collected along with diversity estimate.

\begin{tabular}{|c|c|c|c|c|c|}
\hline \multicolumn{2}{|c|}{ Alamata } & \multicolumn{2}{|c|}{ Raya-Azebo } & \multicolumn{2}{|c|}{ Tanqua-Abergelle } \\
\hline Variety & Frequency & Variety & Frequency & Variety & Frequency \\
\hline Avola & 12 & Jugertie & 1 & Waitozera & 1 \\
\hline Jugertie & 19 & Degalit & 6 & Alaila & 5 \\
\hline Degalit & 13 & America & 17 & Merawi & 13 \\
\hline America & 4 & Degalit+Jugertie & 1 & Kuchiye & 9 \\
\hline Degalit+Jugertie & 1 & Gano & 8 & Debore & 2 \\
\hline Kodem & 1 & Abaere & 4 & Kuanche & 6 \\
\hline Dengele & 2 & Jamuye & 3 & & \\
\hline Wodiakir & 1 & Kodem & 12 & & \\
\hline Gededom & 2 & Baro & 2 & & \\
\hline Hagos-Araya & 1 & Dengele & 11 & & \\
\hline Avoa + Jugertie & 2 & Wodiakir & 2 & & \\
\hline Juru & 2 & $\begin{array}{l}\text { Kodem }+ \text { Jamuye }+ \\
\text { Dengele+Juru }\end{array}$ & 1 & & \\
\hline $\begin{array}{l}\text { America+Dengele } \\
\text { Diversity Indices }\end{array}$ & 1 & & & & \\
\hline Number of landraces & 13 & & 12 & & 6 \\
\hline Number of samples & 61 & & 68 & & 36 \\
\hline $\begin{array}{l}\text { Shannon Diversity } \\
\text { Index (E) }\end{array}$ & 0.77 & & 0.85 & & 0.86 \\
\hline Brillouin Index (E) & 0.77 & & 0.85 & & 0.86 \\
\hline McIntosh's Index (E) & 0.80 & & 0.86 & & 0.86 \\
\hline Margalef Index & 2.92 & & 2.61 & & 1.40 \\
\hline Menhinick Index & 1.66 & & 1.46 & & 1.00 \\
\hline $\begin{array}{l}\text { 1/Berger-Parker } \\
\text { Index }\end{array}$ & 3.21 & & 4.00 & & 2.77 \\
\hline
\end{tabular}

Only four varieties, (comprises about $78.8 \%$ of the total samples) out of the thirteen varieties collected from the villages around Alamata woreda were found to be the most common varieties in the Alamata area (Table. 1). Out of the landraces collected from Alamata (13 landraces comprising 61 samples), three named landraces (local varieties) and two landrace mixtures were sampled only ones that showed their rarities. In this area (Alamata woreda), one variety was named after the selector farmer "HAGOS-ARAYA", but the variety has limited area coverage (sampled only ones). The variety KODEM was sampled only ones and it is rare in the Alamata area, but this variety is one of the most common and widely growing landraces in the Raya- Azebo area. 


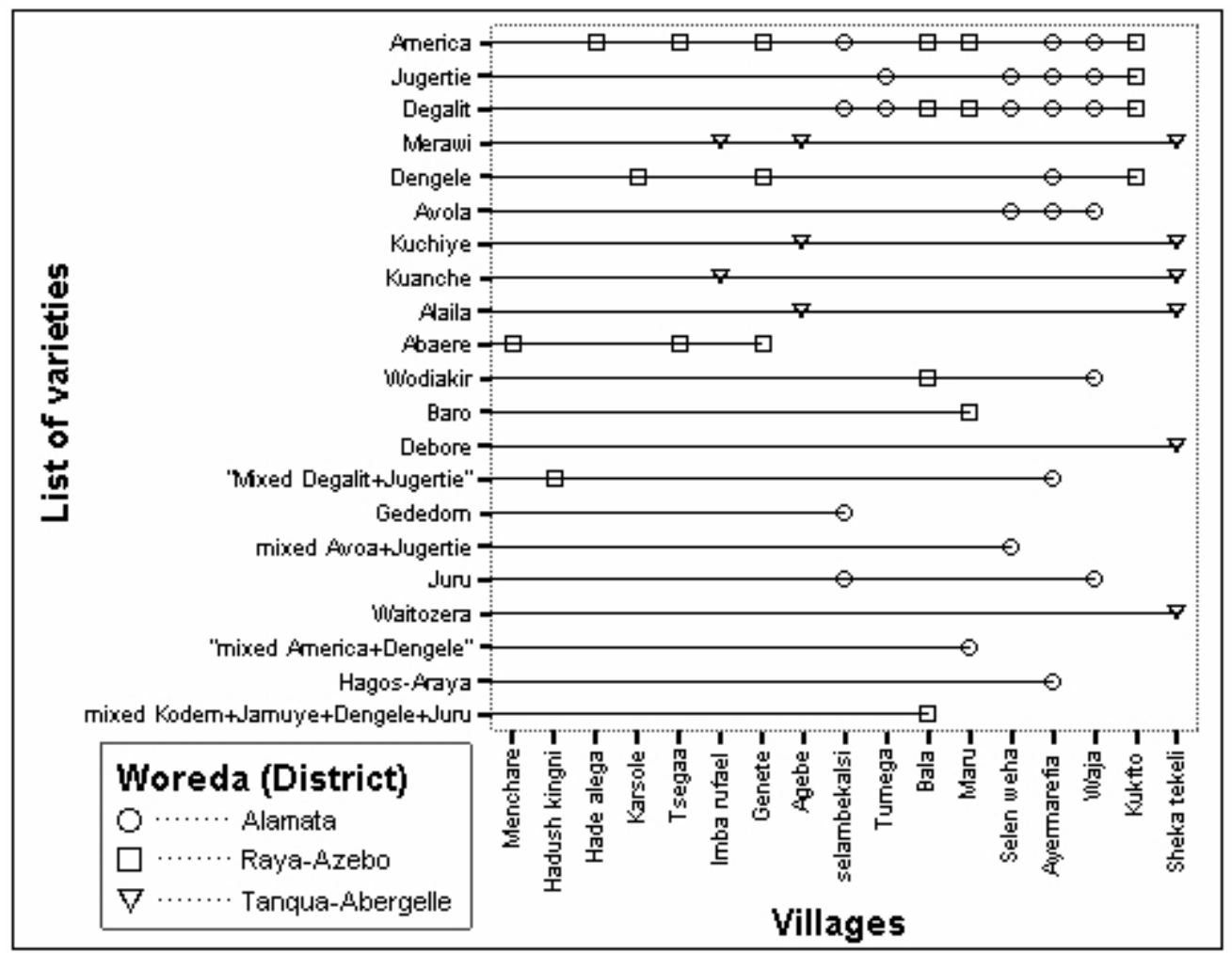

Figure 2. Distribution of sorghum landraces among villages.

Farmers in Alamata and Raya-Azebo areas shared five varieties (Table. 1; Fig. 2). Numbers of varieties that are unique to their specific sites are 3,5 and 6, respectively, for Alamata, Raya-Azebo and Tanqua-Abergelle (Table. 1; Fig. 2). Varieties that are found in Tanqua-Abergelle area are highly specific to their original sites (Table. 1).

Nine of the twelve varieties in Raya-Azebo and five of the six varieties collected from Tanqua-Abergelle cultivated by two and more households. The low frequency of JUGERTIE in the Raya-Azebo (Table. 1) may be due to interchangeably use of the vernacular name "AMERICA" for JUGERTIE. The variety locally named as WAITOZERA was also collected from only a single farmer in the Tanqua-Abergelle area and its declining pattern in frequency were probably associated with the late maturing nature of the variety (as reported by the farmers) as rainfall is the limiting factor in the area particularly during the grain-filling stage.

It is interesting to mention that some of the varieties are sown and harvested in mixtures. For example, Degalit and Jugertie, Avola and Jugertie, America and Dengele are 
landrace mixtures collected in the Alamata area (Table. 1). A mixture of four varieties namely, Kodem + JAMUYE + DENGele + JuRu lumped as a single unit, were also collected and documented in the Raya-Azebo area.

\subsection{Variety occurrence across altitudinal gradients}

Although the sorghum crop is widely grown in the highlands of the south and central Tigray, most of the sorghum varieties were collected from the low land areas of each site; particularly in Alamata area almost all of the varieties were collected in the altitude range of 1400-1600.

Despite the variation in frequency of occurrence, eleven varieties were showed wide adaptation across the elevations (1400-1800) surveyed (data not shown to save a space). Four of the eleven varieties were found in the higher altitude range (1601-1800) and as sorghum is mainly a low land crop. This could probably be a sign of their adaptation to a cooler temperature of the highland, particularly tolerant to cool temperature during the night time.

\subsection{Diversity estimation}

When diversity is estimated based on a number of varieties collected (richness), the Alamata area showed the highest richness $($ Margalef $=2.92$; Menhinick $=1.66)$ followed by Raya-Azebo $($ Margalef $=2.61$; Menhinick $=1.46)$ (Table. 1$)$. Tanqua-Abergelle was found to be less diverse in terms of a number of varieties collected in this study (Margalef $=1.40$; Menhinick $=1.00)$. However, diversity estimated based on evenness indices (McIntosh's index, Shannon diversity index and Brillouin index), Tanqua-Abergelle followed by Raya-Azebo has the highest diversity (Table. 1). The highest evenness found in Tanqua-Abergelle was attributed to the abundance of the varieties across farms and villages (Fig. 2) with the exception of a single variety called Waitozera (found in a single farm). The inverse Berger-Parker dominance model also revealed that the distribution of the landraces in Tanqua-Abergelle was more even than the rest of the woredas (Table. 1).

\subsection{Abundance of local varieties}

Landrace abundance and dominance modelled by geometric series revealed that except in the Alamata area $\left(\chi^{2}=12.24 *, \mathrm{P}<0.05\right)$, there was no significant difference between the observed and expected abundance in both Raya-Azebo $\left(\chi^{2}=2.75, \mathrm{P}>0.90\right)$ and TanquaAbergelle $\left(\chi^{2}=1.13, \mathrm{P}>0.80\right)$ sites. The landraces in the Raya-Azebo and Tanqua- 
Abergelle follow a geometric series. The important explanation of the geometric series model is that the most dominant species (variety in our case) to colonize an area appropriates a fraction of the available resources and the next dominant species (variety) then pre-empts a similar fraction of the remaining resources (environment) and so on. However, the abundance of the landraces in a given agricultural systems mainly determined by the decision making process of the farming community along with some stochastic environmental factors. In this particular study, the abundance of each landraces is assumed to be equivalent to the proportion of the resource allocated by the farmers to each variety they cultivated. In the Alamata area most of the farmers relied on few landraces and most of their resources including the natural capital (land) are allocated into few of the local varieties as it was revealed by the significant chi-square value $\left(\chi^{2}=12.24 *\right)$.

\subsection{Description of some varieties}

The vernacular names, JUGERTIE and AMERICA were usually used interchangeably in the study area although proper characterization work deemed important to substantiate the similarity and/or differences between the JUGERTIE and AMERICA. Probably the variety, JUGERTIE was one of the varieties introduced to south Tigray from elsewhere long-time ago and farmers in the study area consider it as an "introduction", as it is revealed by the vernacular name "AMERICA".

CHIVAY is a variety cited by some farmers as the best variety for consumption purpose as parched or roasted grain while still green, and also as a boiled grain. CHIVAY may have high lysine content, the most important characteristic of palatable and flavored sorghum varieties. It is also used in making the strong distilled liquor (AREKI) and un-distilled local beer (SIWA). The panicle is of open type and has a pinkish seed color. It is reported to have a poor storability, very sensitive to weevil damage. Currently, CHIVAY, Krindayo (open panicle), MAtegola (having compact goose panicle), Atero and WETRO are some of the varieties reported to be locally extinct or under serious threat. BARO, a white seeded variety, is popular for its quality in making ENJERA (Ethiopian flat bread), un-distilled local beer SIWA and the leavened bread КICHA. It is widely grown in the highland areas of south Tigray and adapted to low temperature of the highlands. 
DEGALIT, in some areas called as AvolA, is a variety that has yellow seed color with a goose type panicle. Farmers single out DEGALIT for its significance as a source of quality feed.

GANO (also called as HAFASO in Raya-Azebo) and DENGELE are varieties identified as compact types with goose panicle. Compactness is the most important character in the racial classification of sorghum. We may presume that GANO and DENGELE could be classified as race durra-caudatum, a common race that showed high preponderance in moisture stress areas like that of Tigray Region. Farmers in the Raya-Azebo area of South Tigray also identify GANO as a bird tolerant variety.

JAMUYE, an early maturing type, which suits for making local beer, is characterized as striga resistant variety. Though high yielder, some farmers stated that JAMUYE is highly susceptible to attack by birds and has poor storability.

WAITOZERA is a late maturing variety that has a long stature while MERAWI is an early maturing type, both collected from central Tigray (Tanqua-Abergelle) and known for their sweet grains usually consumed as a green grains by harvesting the milky unripe panicles. MERAWI is also reported to be the best for making quality ENJERA (thin spongy bread regularly consumed throughout Ethiopia).

KUANCHE is a variety collected from the Tanqua-Abergelle area and identified as a drought tolerant variety.

ABAERE and WODIAKIR (both varieties having a short stature) are reported to be wind tolerant and early maturing varieties. ABAERE is reported to have best baking quality. WODIAKIR is a recently introduced variety to the study area from western part of Tigray and getting hold of popularity for its earliness and drought tolerance.

\subsection{Seed system, flow and replacement}

In each cropping season, the household as a unit is the decision-making unit (mainly the household head) that decides which variety and how much seeds of a given variety to plant. In most of the cases farmers in the study area use their own farmer-saved seeds (unless unpredicted factors such as drought acts otherwise) although they may obtain seeds through exchange, gift or purchase. In our study, of the respondent farmers $79.8 \%$ of them responded to retain their produce and depend on their own seeds, while $11.9 \%$ exchange seeds of named varieties in-kind (a reciprocal relationship in which a farmer 
acquires seed by giving seed to another farmer), 5.4\% from neighbours, and 3\% from market (Fig. 3).

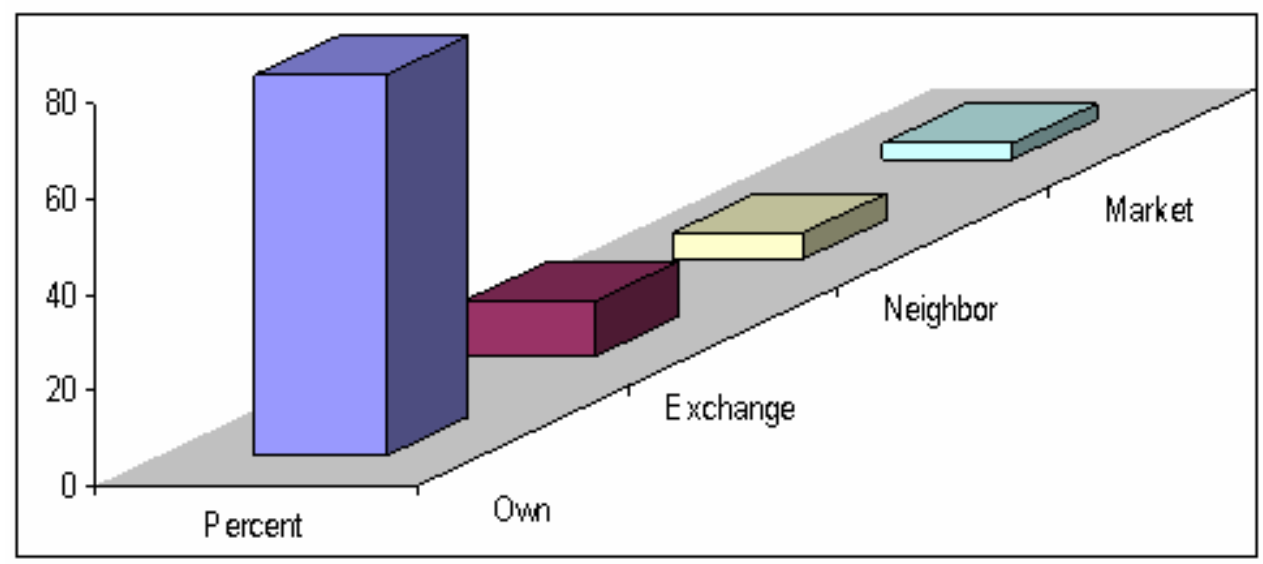

Figure 3. Seed sources.

None of the respondent farmers were users of improved varieties although some of them reported to be beneficiaries of the extension services provided by the office of agriculture and rural development. This was probably due to the absence of modern varieties that suits to their local environment or farmers were reluctant to use them and rather stick to their own genetic resources.

Farmers in the study area stored their seeds in plastic bags, granary with straw roof, storage jars and sometimes in the underground pits. However, the underground pit storage is usually used for grains, as it is very sensitive to mold damage.

The majority of respondent farmers exercise selection before harvesting for a number of traits such as big and long panicles, early maturing types, long stature, straw quality, disease free and good tillering capacity. They also exercise selecting morphotypes from other farmer's field through careful day-to-day observation and get access by making an agreement before harvesting. A number of characters are also mentioned upon which farmers focus when selecting individual plants after harvesting and during storage, such as yield, bigger seed size and color. From the focus group discussion with women farmers, it was noted that women farmers play the leading role in selecting and cleaning seeds from the storage ('koffo' or 'godo') for planting purposes. 
Table 2. Seed replacement schedule.

\begin{tabular}{|c|c|c|c|c|c|}
\hline \multirow{2}{*}{$\begin{array}{l}\text { Reasons of } \\
\text { replacement }\end{array}$} & \multicolumn{5}{|c|}{ Rate of replacement \% } \\
\hline & No & $\begin{array}{l}\text { Every } \\
\text { year }\end{array}$ & $\begin{array}{l}\text { Every } \\
2 \text { years }\end{array}$ & $\begin{array}{l}\text { Every } 3 \\
\text { years }\end{array}$ & If (conditional) \\
\hline No replacement & 48 & - & - & - & - \\
\hline Fertility decline & - & - & 3 & 1 & - \\
\hline Yield reduction & - & 1 & 5 & 1 & - \\
\hline Striga problem & - & 1 & 4 & 12 & 1 \\
\hline Rain shortage & - & - & - & - & 16 \\
\hline Total & $\begin{array}{l}48 \\
(51.1 \%)\end{array}$ & $\begin{array}{l}2 \\
(2.2 \%)\end{array}$ & $\begin{array}{l}12 \\
(12.9 \%)\end{array}$ & $\begin{array}{l}14 \\
(15.1 \%)\end{array}$ & $\begin{array}{l}17 \\
(18.3 \%)\end{array}$ \\
\hline $\mathrm{N}$ & 93 & & & & \\
\hline Phi $\Phi$ & $1.48^{* *}$ & & & & \\
\hline Cramer's V & $0.742 * *$ & & & & \\
\hline$x^{2}$ (Chi-square) & $204.82 * *$ & & & & \\
\hline Fisher's exact test & $164.451^{* *}$ & & & & \\
\hline
\end{tabular}

Seed replacement, the replacement of home grown varieties by fresh varieties from various sources including exchange and market, were also documented in this study (Table. 2). Farmers may replace seeds of their named varieties if they believe that the varieties are deteriorated in quality through repeated recycling to the point that replacement becomes desirable. However, a majority of the farmers in the present study depend on farm saved seeds every year (51.1\%), some $18.3 \%$ of the farmers reported to exchange their seed stocks on condition that mainly during crop failure resulted from rainfall shortage, and these values were significantly different from each other (Table.2). This kind of strategy depends on maturity pattern of the varieties that early maturing ones could serve for replanting purposes during complete crop failure. Striga problem and yield reduction were noted as a driving force for replacing varieties every two-three years.

\subsection{Temporal diversity pattern and genetic erosion}

Temporal diversity (rate of change over time) over a period of ten years were assessed in this study based on the data from a recent sorghum landraces collection mission (in the year 2007) in south (Alamata and Raya-Azebo) and central Tigray (Tanqua-Abergelle), and a census made by the Tigray Bureau of Agricultural and Rural Development in the year1997. About twelve varieties collected in the recent collection mission were not 
reported in the 1997 census and the varieties of recent collection showed a frequency range from 1-21 (Fig. 4). Five varieties reported from the initial census (year 1997) were missing from the recent collections. On the other hand, about eight varieties reported from the initial census were also found in the present collection mission. Over ten years assessment, the temporal diversity based on the variety richness was found to increase from the expected.

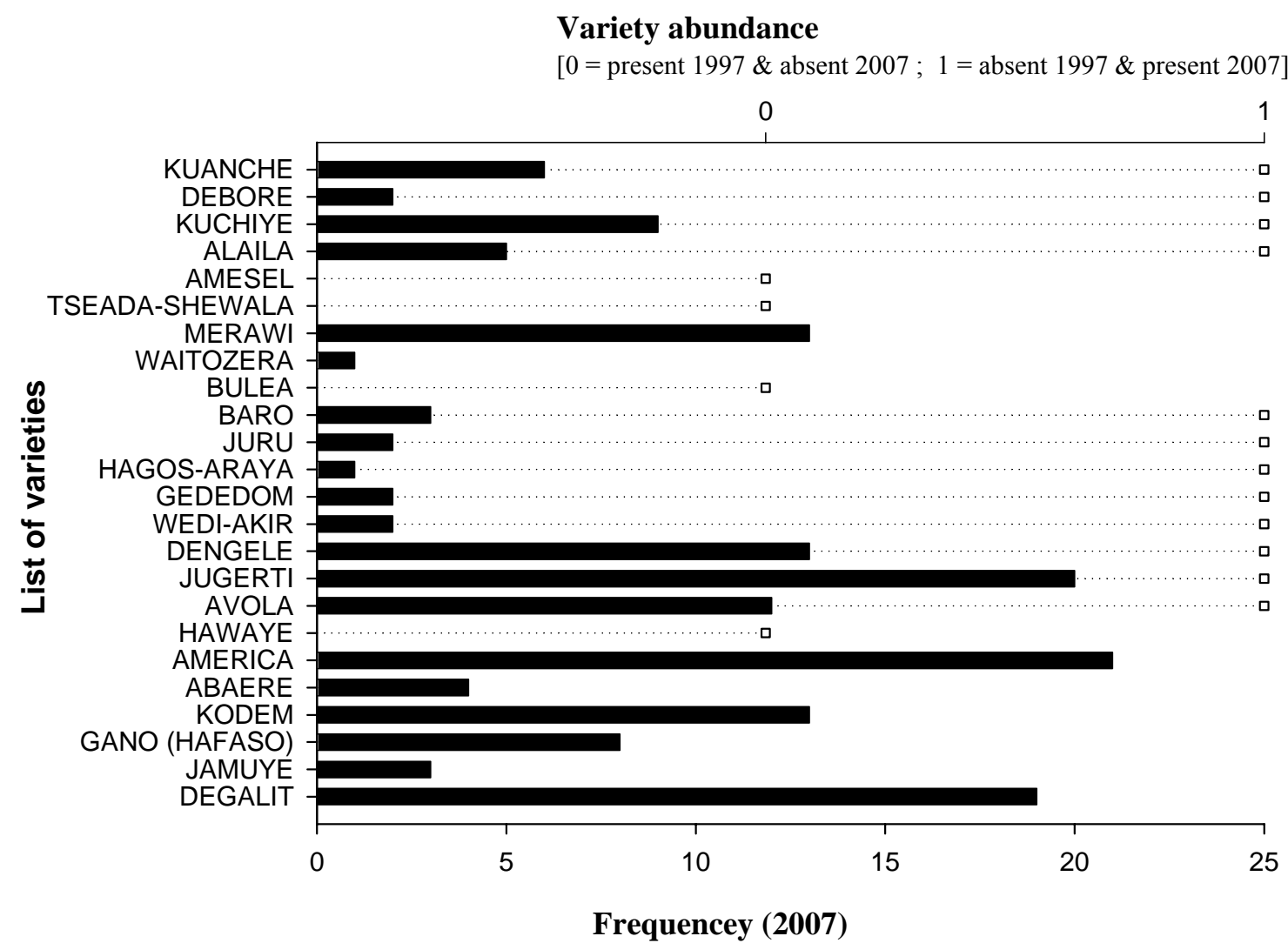

Figure 4. Variety abundance over ten years and their frequency.

Genetic integrity and genetic erosion was calculated to assess the pattern of temporal diversity over 10 years (from 1997-2007) and to estimate the level of genetic erosion. Based on the model of genetic integrity and genetic erosion given in the methodology part of the paper, the genetic integrity was about $154 \%$ (>100\%) like wise the genetic erosion was a negative value $-54 \%$. No loss of genetic integrity was found over those years and also the level of genetic erosion was insignificant. Nevertheless, the model has several limitations that usually depend on the presence or absence of a particular variety or species during a collection mission done in a given specific time. This model 
underestimates the crop rotation schemes and informal seed exchange systems exercised by the farming community that it is often possible that a given variety of a crop or species may not be seen at the time of collection mission without being lost.

On the contrary to the area based island biogeography model, the double logarithmic model (log-log plot, parcels vs. variety richness) developed in this study best predicted the increase in varietal richness with increasing number of parcels that as the number of parcel increases farmers could get more option to manage several varieties in each patches (Fig. 5), so that the loss of landraces would be minimal. The steepness of the slop in the regression model reveals the increase in landraces richness as the number of parcel (plots) increases.

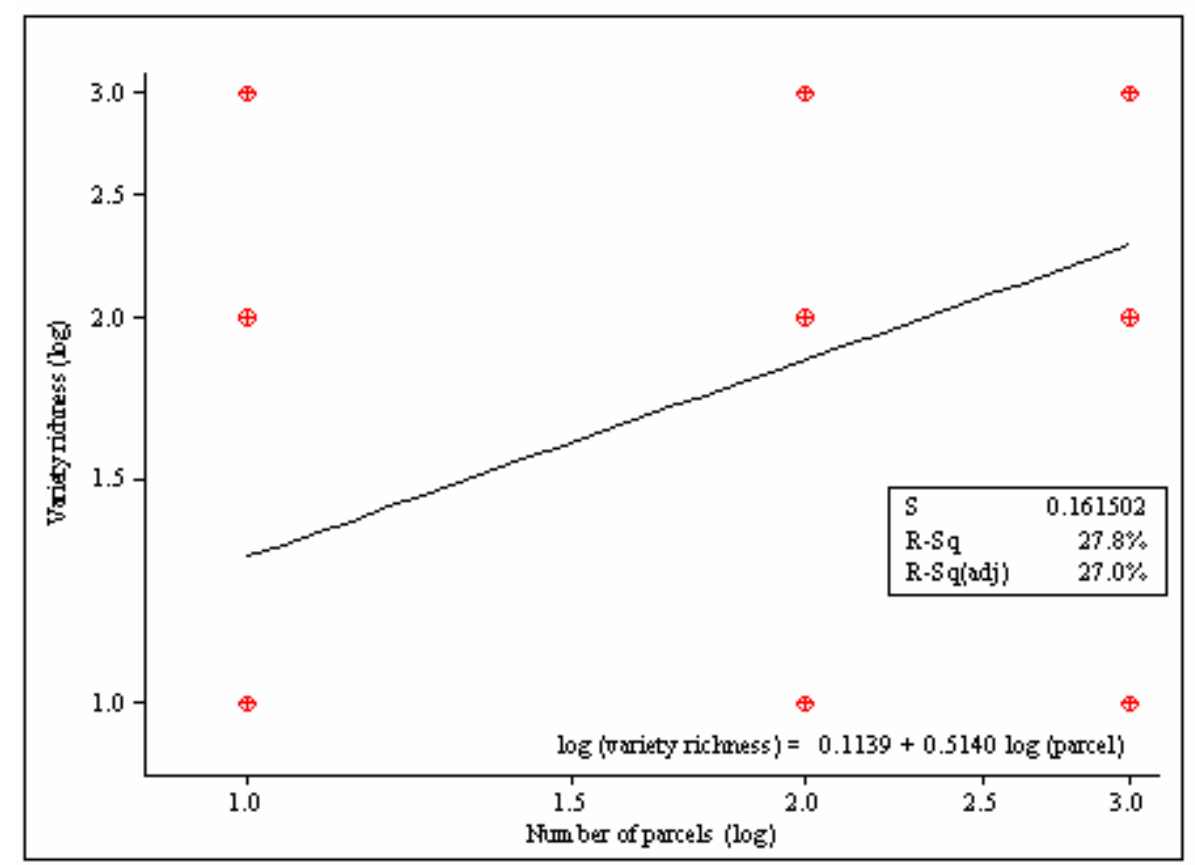

Figure 5. Effect of number of parcels (plots) on varietal richness

\subsection{Diversity regression}

The regression analysis revealed that richness of sorghum landraces based on area share is highly associated to the number of parcels (Table. 3). High levels of fragmentation could also reflect that the household natural capital endowment is not contiguous that leads to a number of production niches. 
Table 3. Poisson regression analysis on factors affecting intra-crop diversity.

\begin{tabular}{|lll|}
\hline Variables & Coefficient & $\mathbf{P}>|\mathbf{Z}|$ \\
\hline Constant & -5.827 & 0.193 \\
Household characteristics & & \\
Age & 0.045 & 0.566 \\
Year of schooling & -0.124 & $0.012^{* *}$ \\
Farming experience & -0.041 & 0.720 \\
Year of growing sorghum & -1.191 & 0.125 \\
Labour equivalence & -0.269 & $0.016^{* *}$ \\
Dependency ratio & -0.803 & 0.301 \\
Age-experience ratio & 3.508 & 0.457 \\
Farm characteristics & & \\
Altitude & 0.002 & 0.350 \\
Land size & 0.121 & 0.462 \\
Number of oxen & 0.202 & 0.365 \\
TLU & -0.299 & $0.009^{* * *}$ \\
Number of parcels (plots) & 0.683 & $0.000^{* * *}$ \\
Distance to market & -0.008 & $0.015^{* * *}$ \\
Attribute importance & & \\
End uses & -0.091 & 0.476 \\
Sites & & \\
Alamata & 3.056 & $0.000^{* * *}$ \\
Raya-Azebo & 2.661 & $0.000^{* * *}$ \\
Tanqua-Abergelle & 4.367 & $0.000^{* * *}$ \\
\hline & & \\
$\mathrm{N}=93$ & & \\
LR $\mathrm{X}^{2}(17)=176.80$ & & \\
Prob $>\mathrm{X}^{2}=0.0000$ & & \\
Pseuso ${ }^{2}=0.4353$ & & \\
Log likelihood $=-114.686$ & & \\
$* \mathrm{P}<0.10, * * \mathrm{P}<0.05, * * * \mathrm{P}<0.01$ & & \\
\hline
\end{tabular}

Socio-demographic characteristics of the household (human capital) such as age, farming experience, years of growing sorghum, dependency ration, and age-experience ratio appear to bear no relationship to the richness of area share of sorghum landraces (Table.3). However, year of schooling and labour equivalence were perceived to have a negative association and were significant factors explaining variation in sorghum diversity among households in the two zones (South and central Tigray) studied. Since the labour equivalence index can be affected by large family size that comprises of very young household members (less labour contribution), and at the same time maintaining multiple varieties requires additional time, cultivating fewer varieties may relieves labour 
constraints. On the other hand, farmers with less formal education tend to diverse their crops as a mechanism of avoiding risk and meet multiple needs of the household that depend on the unique characteristics of different varieties than farmers with a formal education, as the latter usually focuses on limited number of varieties with a specific character, mainly yield.

The large number of livestock assets as measured by TLU (Tropical Livestock Unit) is associated with low richness area share that probably lead farmers to specialization as it is revealed by the regression analysis (Table. 3). This could also show the presence of a certain degree in livestock market involvement thus predisposed in their attitudes against high level of varietal richness.

Household further away from main markets grow more landraces. The more removed a household from a market center, the higher the costs of buying and selling on the market and the more likely that it relies primarily on its own production for subsistence that leads to diversification.

The study zones, both south and central Tigray, displayed great diversity in richness area share of sorghum (Table. 3), as the woredas (Alamata, Raya-Azebo and TanquaAbergelle) are the main sorghum producing areas in Tigray Region and the existing agroecological heterogeneity among and within the sites is instrumental in fostering higher sorghum genetic variability.

\section{DISCUSSION}

\subsection{Vernacular names and abundance}

Factors which farmers use to identify and shape farmers' varieties are complex and interrelated, and farmers perceive these factors at various stages throughout the growth period (Berg, 1993). The name or description of a farmer's variety that farmers give to their local varieties may be related to the original source of the material, morphology, end uses etc. Nevertheless, vernacular names may not always correspond to botanical distinctiveness, although they are quite often descriptive of the variety grown. For example, the vernacular name given to a variety called KODEM, a variety that is widely grown in Raya-Azebo area, could be derived from the name of the "race caudatum" as linguistically very similar and morphologically a typical caudatum type. Caudatum 
sorghum has characteristic turtle-backed grains that are flat on one side and distinctly curved on the opposite side (Doggett, 1988), and it is one of the common sorghum races in the Tigray Region. The grain of the caudatum sorghum is usually exposed between shorter glumes at maturity and its inflorescence ranges in shape from compact to open. Particularly the compact panicle shaped sorghum is the dominant type sorghum in the study area. Some varieties are also named after the farmer who selected and developed the variety. For example, in the Alamata woreda, one variety is named by the name of the selector farmer "HAGOS-ARAYA" and despite the limited area coverage of such a landrace (sampled only ones), the practice shows the dynamic nature of the process and farmers' desire to develop varieties suitable for variable soils and environmental conditions. This observation was similar to that reported by Tsehaye et al. (2006).

Some varieties were found to be locally frequent and others were locally rare (Fig. 2). The dominance/abundance of some varieties could be associated with the use values (end uses, superior agronomic characteristics) and market demand linked to the varieties in the rural settings. The dominance of certain varieties in respective wordas could also be associated with adaptability of the varieties to the existing microenvironment of the study area and also existence of high proportion of locally common alleles of adaptive significance. However it is not clear whether the level of variability in the common varieties tend to be larger than the less common varieties in terms of allelic richness.

\subsection{Seed source and exchange}

In this study, farmer-saved seeds account for most of the seeds used (Fig. 3). The farmers in study area also obtained seeds from various sources, such as exchange, neighbours and market, through payment in cash. The flow of seeds of named varieties from nearby spatial scales and villages was evident in this study (Fig. 2). For example, there was much similarity between the names of sorghum varieties grown in both Alamata and RayaAzebo woredas, as the two sites are close to one another, the informal seed exchange as part of the local network might affect and stimulate local exchange of the varieties and also sharing knowledge.

In some seasons (bad seasons), poor families particularly women migrates temporarily to distant places to glean the stocks and panicles that fall to the ground during harvesting. This is a common practice in the south Tigray and usually called as "QARMIA'. Gleaning 
and gathering in the field until evening after the reapers is a tradition left to the poor and it is instrumental in disseminating seeds of different varieties into different places. This tradition may have an interesting connection to the harvest festival of ancient Judea mentioned in Book of Ruth, in the Bible, that allows the poor to glean during harvesting. It is interesting to mention here that some varieties widely grown in south Tigray have linguistic similarity with those grown in south Welo. For example, Juru, Degalit, Jugertie and Jamuye that are popular in south Tigray are very similar to those documented by Teshome (1996) in south Welo. Farmers' practice of exchanging seed lots for the same named varieties across different large spatial scales has been noted in a number of studies (e.g. Almekinders et al., 1994; Tsehaye et al., 2006), though a through assessment of the direction of the flow, the structure of the genetic diversity within the landraces as well as the ethnobotanical knowledge associated with the landraces at respective sites deemed important for better understanding and utilization of the landraces. Moving landraces within and/or across similar ecological zones could be a powerful way of improving production stability. Seed exchange network can be established as a means of facilitating access to locally adapted sorghum genetic resources. However, this may require the establishment of mini-community seed banks (Satellite seed banks) designed and managed by farmers themselves. The satellite community seed banks could facilitate mobilizing masses of useful local germplasm at faster rate and can reduce transaction costs. A list cost permafrost genebank can also be established, for instance, at a mountain peak called Tsibet (south Tigray), that serves as a long and short term storage and this can also be linked to mini-community seed banks that can be established at community level.

The level of diversity (both richness and evenness) estimate detected in all the sites surveyed in this study revealed that most of the villages (sites) are of paramount significance for the establishment of on-farm conservation programmes. Based on the variety richness and use values attached to each landraces, however, two sites in Alamata (Ayenmarefia and Waja), one village each in Raya-Azebo (Kukftu) and TanquaAbergelle (Shekatekli) could serve as a seed repositories by establishing community seed banks (see Fig. 2 for varietal richness). 


\subsection{Landrace management}

Maintaining varieties in mixed state were found to be a practice exercised by some farmers in both Alamata and Raya-Azebo woredas (Table. 1) and in this type of mixtures, it was the inflorescence morphology (panicle morphology) that matters. In a recent study, Teshome et al. (2007) reported that farmers in south Welo were found to include a substantial infra-specific and inter-specific crop diversity in their field and over 30 different sorghum landraces (named varieties) were identified in a single field. From the farmers perspective a number of reasons can be provided for mixing varieties together during planting and harvesting but of all the reasons, seed and harvest security as well as harvest assurance might be the main reasons behind mixing the varieties, as the varieties have different maturity and microenvironment requirement (e.g. rainfall, growing degree days etc). This exercise could also allow the farmers to exploit different microclimates and derive multiple nutritional values and harvest security in time of unpredictable environmental stress. According to Brush (1992), maintaining in mixtures is an object of selection for cultural reasons, taste, gifts, local identity, and for potential future markets.

One of the main characteristics of the traditional sorghum farming of the study areas is farmer management of environmental heterogeneity by cultivating different sorghum landraces in different plots, which vary in their elevation and microenvironments. Although sorghum is a lowland crop and the altitude range showed a positive but nonsignificance association with diversity area share (Table. 3), households quite often had sorghum plots at higher points; this is probably associated with risk avoidance due to frequent drought in the lowlands and adaptability of some of the local varieties to a cooler temperature of the highlands. This was made possible by land fragmentation (different parcels of farm land), a common phenomenon in the study area. Although the level of diversity supported by each plot (farm) and the effective population size requires morphological and/or molecular assessment, it is evident that land fragmentation or having different parcels of farm land could support more landraces at household and village levels. Brush (1999) also noted that fragmentation of landholdings allows farmers to manage several fields, possible heterogeneous, and cultivated landraces in at least one filed. The physical fragmentation of farmers' fields may facilitate the biological 
fragmentation of sorghum landraces and allow the evolution of new landraces through temporal and spatial isolation (Tunstall et al., 2000). The double log regression model developed in this research work also showed the significance of land fragmentation to overall diversity (richness). However the moderate $\mathrm{R}^{2}$ value (about $28 \%$ ) obtained in the regression analysis revealed that still about $72 \%$ of the variance was not explained by this model, as other factors (environmental as well as anthropogenic) could also affect the overall diversity.

\subsection{Genetic erosion}

The theoretical hypothesis of genetic erosion resulted from the introduction of improved varieties (introduction of improved varieties $=$ loss of genetic diversity) usually obscured by the traditional seed systems and farmers demand for stability and seed as well as livelihood resilience. In the present study none of the farmers interviewed were reported to cultivate an improved variety of sorghum as well as use of inorganic fertilizers for sorghum production. Stability of production that is lower production, which is consistent from season to season, is greatly to be preferred by the farmers that drive farmers to their locally adapted varieties. As a result, the extension effort of introducing improved varieties (not properly tested at local condition) along with the associated input across to the local farmers met with little success particularly in the sorghum growing areas of this particular study. The farmer has no buffer system that a cycle of surplus and crop failures places him and his families in a hazardous position (Doggett, 1988) that stability of production must be achieved to the greatest possible extent using the local varieties (farmer's varieties).

The level of genetic erosion as tested based on temporal diversity over ten years time were minimal that shows the complex nature of the concept. Using several models for estimating genetic erosion on sorghum from Eastern Ethiopia, Mekbib (2008) noted that there was no significant loss of sorghum landraces over 30 years. In general, an assessment of genetic erosion of crop populations in centers of crop diversity such as Ethiopia is at an impasse. On one hand, general but under-theorized models of agricultural change present a logical argument for genetic erosion. This argument, however, has not been rigorously tested, and it does not contend with environmental heterogeneity-either social or bio-physical-in farming systems. On the other hand, 
specific but equally under-theorized descriptions of landraces that compete with modern varieties suggest that survival of crop diversity is plausible in certain environments (Brush, 1999). Nevertheless, with fairy frequent drought and extensive history of famine, starting from 253 BC (Unruh, 2002, unpublished report), how the Ethiopian farmers particularly the Tigrayan farmers (resides in the drought prone region) have been able to maintain significant genetic diversity of several crops including sorghum remain as unresolved question yet. The process through which genetic resources are maintained over time and access to seeds is secured over several shocks are often, poorly understood or under-appreciated (FAO, 2003). It would be useful to investigate the relationship between the processes of genetic erosion, informal seed exchange network and cultural ecology nexus.

\section{CONCLUSION}

The management and enhancement of plant genetic resources including sorghum has been in the hands of the farming community from the beginning of agriculture. The contribution of farmers is critical to the conservation, use and enhancement of biodiversity. The Convention on Biological Diversity (CBD), which came into force in December 1993, has for the first time in a legally binding document given explicit recognition to the role of farmers to both accumulation and conservation of genetic resources and knowledge. The document emphasize that the future of world food security depends not just on the stored crop genes ex situ, but on the people who use and maintain diversity on daily basis.

In the present study farmers managed to maintain more than thirty locally named varieties. The causes for the present de facto in situ conservation of traditional sorghum varieties, as Brush (1999) stated it, could be the fragmentation of landholdings, cultural identity and preference for diversity, economic isolations as well as marginal agronomic conditions. Many of the sorghum local varieties are exquisitely fitted to the specific niches and highly associated with the livelihood of the subsistence farmers. Their positive contribution in enhancing livelihood resilience (the ability of the community to return to equilibrium after a perturbation) in the face of risk, stresses and shocks is of great significance. Moreover, access to the sorghum seeds and other plant genetic resources is 
crucial element of food security and sustainable development as plant genetic diversity, embodied in seeds, enables adaptation to changing economic and environmental conditions and supports diverse livelihoods in obvious and not-so-obvious ways. At present, sorghum has never been developed as a major food for urban dwellers. It is only serving as a source of the popular local beer (SWA) in the urban areas. Lacking markets, it remains a crop of the small-scale producers, consumed largely on the place where it is produced. But this need not continue in this way, it requires attention that the policy makers and public funded governmental institutions should support its production through a number of means including price and policy formulations. By creating a market and non-market incentives, it would be possible to support the ongoing efforts of farmers to manage and improve their sorghum genetic resources. It may also be appropriate to assess different options for adding values to the local varieties (including participatory plant breeding), thus, increasing the benefits that farmers get from cultivating diverse local crop resources in a given social, economic and ecological context. On-farm conservation programmes can be designed as a way of improving farmer's incentives by adding befits to landrace production and supporting farming systems associated with genetic diversity.

\section{ACKNOWLEDGEMENTS}

We thank all the farmers of the study area who were involved in the survey and shared their valuable knowledge and their genetic resources. We also thank MU for the financial and logistic support during the fieldwork. Finally, the comments and suggestion given by the anonymous reviewers is appreciated.

\section{REFERENCES}

Almekinders, C.J.M., Louwaars, N.P \& de Bruijn, G.H. 1994. Local seed systems and their importance for an improved seed supply in developing countries. Euphytica, 78: 207-216.

Ayana, A \& Bekele, E. 1998. Geographical patterns of morphological variation in sorghum (Sorghum bicolor (L.) Moench) germplasm from Ethiopia and Eritrea: qualitative characters. Hereditas, 129: 195-205. 
Bellon, M.R. 1996. The dynamics of crop infraspecific diversity: A conceptual framework at the farmer level. Economic Botany, 50:26-39.

Berg, T. 1993. The science of plant breeding-support or alternative to traditional practices? In: W. De Boef., K. Amanor., K.Wellard and A. Bebbington (Eds.), Cultivating knowledge: genetic diversity, farmer experimentation and crop research. Intermediate Technology Publications Ltd, UK, 72-77 pp.

Brown, W.L.1983. Genetic diversity and genetic vulnerability-An appraisal. Economic botany, $37(1): 4-12$.

Brush, S.B.1992. Ethnoecology. Biodiversity, and modernization in Andean potato agriculture. J. Ethnobiol., 12:161-185.

Brush, S.B.1995. In situ conservation of landraces in centers of crop diversity. Crop Sci., $35: 346-354$.

Brush, S. B.1999. Genetic erosion of crop populations in centers of diversity: A revision. Proceeding of the technical meeting on the methodology of the FAO world information and early warning system on plant genetic resources. Prague, 2123 June 1999.

Doggett, H. 1988. Sorghum. Longman group UK limited.

FAO. 1998. The soil and terrain database for north-eastern Africa: crop production system zones of IGAD sub-region. Rome.

FAO. 2003. Understanding access to seeds and plant genetic resources. Livelihood Support Programme (LSP). Working paper 6.

Frankel, O.H. 1970. Genetic conservation in perspective. In: O.H. Frankel and E. Bennett (Eds.), Genetic resources in plants-The exploration and conservation. Blackwell Scientific Publications, Oxford, 469-489 pp.

Hammer, K., Knupffer, H., Xhuveli, L \& Perrino, P. 1996. Estimating genetic erosion in landraces-two case studies. Genet Resour Crop Evol., 43:329-336.

Harlan, J.R. 1971. Agricultural origins: Centers and noncenters. Sceince, 174: 468-473.

Harlan, J.R. 1992. Crops and Man. $2^{\text {nd }}$ Edition, Am. Soc. Agron. and Crop Soc. Am., Madison, WI.

Hawkes, J.G. 1983. The diversity of crop plants. Cambridge, MA: Harvard University Press. 
Kebede, Y. 1991. The role of Ethiopian sorghum germplasm resources in the national breeding programme. In: J.M., Engels, J.G. Hawke and M. Worede, (Eds.), Plant Genetic Resources of Ethiopia. Cambridge University Press, Cambridge, 315-322 pp.

Magurran, A. 1988. Ecological diversity and its measurements. Princeton University Press, Princeton, NJ, USA.

McArthur, R.H \& Wilson, E.O. 1967. The theory of island biogeography. Princeton University Press, Princeton, NJ, USA

Mekbib, F. 2008. Genetic erosion of sorghum (Sorghum bicolor (L.) Moench) in the centre of diversity, Ethiopia. Genet Resour Crop Evol., 55:351-364

National Research Council. 1996. Lost crops of Africa: Grains. 1. National Academy Press, Washington, D.C.

Stiling, P. 2002. Ecology-Theories and applications. $4^{\text {th }}$ Edition, Prentice-Hall, Inc New Jersey, USA.

Teshome, A. 1996. Factors maintaining Sorghum [Sorghum bicolor (L.) Moench] Landrace diversity in north Shewa and south Welo Regions of Ethiopia. Ph.D Thesis, Department of Biology, Ottawa-Carleton Institute of Biology, Carleton University, Ottawa, Ontario, Canada (unpubl.).

Teshome, A., Patterson, D., Asfaw., Torrance, J. K \& Arnason, J.T. 2007. Changes of Sorghum bicolor landrace diversity and farmers' selection criteria over space and time, Ethiopia. Genet Resour Crop Evol., 54:1219-1233.

Tripp, R. 1996. Biodiversity and modern crop varieties: Sharpening the debate. Agriculture and Human Values, 13(4): 48-63.

Tsehaye, Y., Berg, T., Tsegaye, B \& Tanto, T. 2006. Farmers' management of finger millet (Eleusine coracana L.) diversity in Tigray, Ethiopia and implications for on-farm conservation. Biodiversity and Conservation, 15:4289-4308.

Vavilov, N.I. 1951. The origin, variation, immunity and breeding of cultivated plants. Chron. Bot., 13: 1-366.

Wood, D \& Lenné, J.M.1997. The conservation of agrobiodiversity on-farm: questioning the emerging paradigm. Biodiversity and Conservation, 6:109-129. 